\title{
Global Effects in Kashaya Prosodic Structure
}

\author{
EUGENE BUCKLEY \\ UNIVERSITY OF PENNSYLVANIA
}

In Kashaya, an endangered language belonging to the Pomoan family of northern California, there is a stark difference in the patterning of vowel length according to the morpheme in which the vowel is located. The verb root and a large set of inner suffixes undergo various lengthenings, whereas another large set of suffixes, located outside the first set, does not participate in any of these alternations. Buckley (1994a) posits five lexical levels for Kashaya, but with minimal changes these can be reduced to two strata matching the more typical grammar in Lexical Phonology (Kiparsky 1982) or the Stem and Word in Stratal Optimality Theory (Kiparsky 2000, Bermúdez-Otero 2011); these labels then identify the two sets of suffixes. In this paper I explore the complex interaction between the changes to vowel length and the morphological affiliation of the morphemes in question, with special reference to the apparent global effect across the two lexical strata.

The paper is organized as follows. Sections 1 and 2 describe the complex but regular stress pattern of Kashaya, including its effect on vowel length and its interactions with morphological structure. Section 3 demonstrates the problem of generating the right Stem form on the basis of the first following Word suffix, and considers ordered solutions that rely on special intermediate representations. Section 4 pursues various potential global and look-ahead effects, in approaches ranging from constraint-based Optimality Theory to the stepwise rules and spell-out of Distributed Morphology. Section 5 summarizes the issues that arise in the different perspectives. Although I present several possible analyses in diverse theoretical approaches, my goal is not to argue that only one of them is plausible. Instead, I seek to show practitioners of a variety of 
frameworks what changes are necessary to their theories in order to accommodate the complex pattern of Kashaya foot structure and vowel length.

\section{An overview of Kashaya stress}

Kashaya is a member of the Pomoan family, spoken in northern California (Oswalt 1961, Buckley 1994a). It has a very complex but almost entirely regular metrical system that can place the stress on any of the first five syllables of a word, depending on the length of the root and the distribution of closed syllables and long vowels. Since the main discussion in this paper revolves around certain features of the metrical system, I first give an overview of the various components. Although Kashaya stress is often placed on phrases of more than one word (Buckley \& Gluckman 2012), the question of interest here is relevant mainly within long words and phrasal stress will be addressed only briefly. The data in this paper are from Oswalt $(1961,1964,2005)$.

Metrical structure in Kashaya is iambic, constructed from left to right in a stepwise approach (Buckley 1994b) or aligned toward the left in a constraint-based theory (Buckley 1997). As expected under this basic pattern, stress falls on the first syllable if it is heavy, otherwise on the second. Since morphological bracketing plays an important role, roots of all complex words are shown in boldface, and square brackets mark two domains that are also crucial, the Stem and Word, to be discussed more thoroughly below. Within the Stem domain (the inner brackets), any vowel that heads a foot and occurs in an open syllable undergoes Iambic Lengthening.

(1) a. [ [ mo-mul-ic'-ed ] u ]

( mo mú· $)($ li c’e· $) d u$

'run in circles'

b. [ [ cad-uced ] un ]

( ca dú• ) ( ce dun )

'while looking' 
c. [ [ kel-mul-ad-uced ] u ]

$($ kél ) ( mu la· ) ( du ce· ) du

'keep peering around'

Since there is no explicit evidence for degenerate feet except when required for the main stress (illustrated below), they are assumed in these representations only in that special case.

\subsection{Syllable extrametricality}

A central fact about Kashaya stress is that the first syllable is extrametrical by default (Buckley 1994a,b); this special status is marked as «> here. This extrametricality is blocked when the second syllable of the word is suffixal, as in the examples just presented. But in most words of the language, either the root is at least two syllables in length, or the first syllable is an instrumental prefix and followed by a root of one or more syllables. As a result, the vowels that undergo Iambic Lengthening are shifted one syllable to the right, and the stress occurs on a heavy second syllable, otherwise on the third syllable.

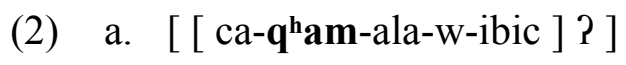

〈ca〉 ( q⿳a má· ) ( la wi· ) ( bi? )

'start to cut downward'

b. [ [ qa?c'at-ad-uced ] u ]

〈qa?〉 ( c’a țá $)($ du ce· ) du

'used to cry and cry'

c. [ [ qa?c'at ] $\mathrm{Pk}^{\mathrm{h}} \mathrm{e}$ ] thin

〈qa?〉 ( c’át’ ) ( ke thin )

'shouldn't cry'

More formally, syllable extrametricality occurs in disyllabic or prefixed roots, but is blocked for monosyllabic unprefixed roots. 


\subsection{Stress shift}

Left-edge extrametricality is somewhat unusual in the world's languages, although clearly attested in some cases (Buckley 2009, Kager 2012). What makes Kashaya additionally noteworthy is the presence of stress shift onto the second foot in the representation. In past work I have analyzed this formally as foot extrametricality (Buckley 1994b, 1997), but it would also be possible to treat it as a shift in the accent one syllable to the right. In this paper I use the notation «» to mark feet that are extrametrical, or that in some other way lose their prominence to the immediately following foot.

The most straightforward instantiation of stress shift in Kashaya occurs when the leftmost syllable of the word is $\mathrm{Cv} \cdot$ - that is, a nonbranching foot containing a long vowel. This length can be underlying or derived by elision of two adjacent vowels.

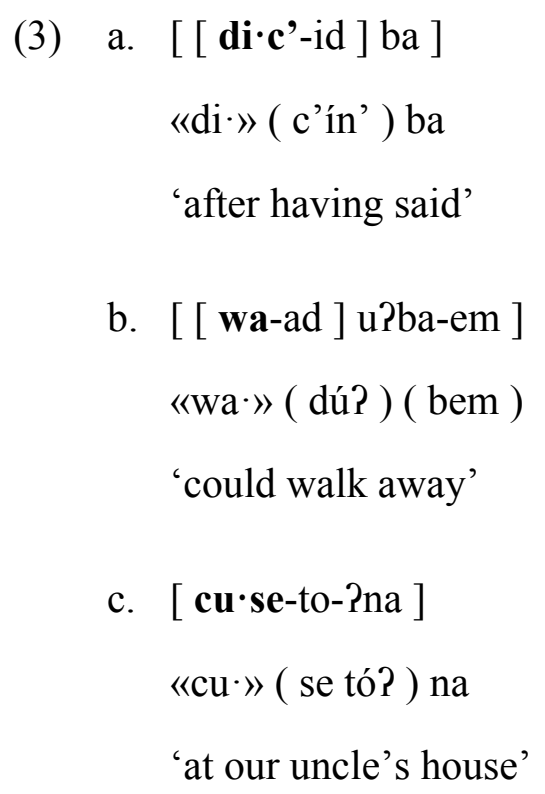

The last word is not marked for the Stem because it belongs to a morphological category in which it is more difficult to diagnose that constituent.

As with syllable extrametricality, this simple stress shift (whether or not it is formally treated as foot extrametricality) yields stress on the second or third syllable of the word, 
depending on weight. But the two phenomena cannot be collapsed, because they are independent and often cooccur. A word that is eligible for syllable extrametricality due to the position of the root often has a long vowel in the next syllable $-\mathrm{a} \mathrm{Cv}$. foot that is initial relative to syllable extrametricality - and in that case the two displacements are additive. In other words, the two phenomena are cumulative when the root is disyllabic or prefixed.

a. [ [ du-Pya·q-ad-qa ] ba ]

〈du?» «ya·» ( qán’) ( qa ba )

'after thinking about it

b. [ [ ba-ne-aduc-qa ] /li ]

〈ba〉 «ne·» $\left(\right.$ dúc $\left.{ }^{\mathrm{h}}\right)(\mathrm{qa} \cdot)$ li

'when (they) sent it off in the distance'

c. $[[$ šula $\cdot \mathbf{m}] \mathrm{i}$ iba $]$

〈šu〉 «la·» ( má? ) ba

'would get sick'

In these examples, the third syllable of the word receives the stress because it is heavy. When that syllable is light, we find a further pattern that is of special interest in this paper, to which I now turn.

\subsection{Foot Flipping}

The application of Iambic Lengthening to the sequence $\mathrm{CvCv}$ results in a "perfect iamb", $\mathrm{CvCv}$, and this is a common sequence of syllables in Kashaya as well as many other iambic languages (Hayes 1995). A more unusual aspect of Kashaya is that an initial sequence of the shape $\mathrm{Cv} \cdot \mathrm{Cv}$ is "flipped" with respect to syllable weight to produce the same $\mathrm{CvCv}$ ' found in other contexts. Although this change, named Foot Flipping by Buckley (1994b), is not syllabically distinct from a $\mathrm{CvCv}$ that has undergone Iambic Lengthening, it does remain prosodically distinct, because the 
flipped foot is subject to the same stress shift found for $\mathrm{Cv} \cdot$ that is not eligible for Flipping (for various reasons discussed below); in other words, the entire flipped foot behaves as extrametrical.

(5) a. [ [ t'e-t-ibic $]$ ba $]$

«t'e ti·» ( bíc') ba

'having stood up'

b. [ [ ca-ad-uced ] u ]

«ca du•»( ce dú $)$

'flies along'

c. [ [ di·c'-id-uwad-uced ] u ]

«di c'i•»( du wá· $)($ du ce• $)$ du

'he used to tell (this story)'

As with the simple stress shift that applies to $\mathrm{Cv}$, Foot Flipping combines freely with syllable extrametricality. Consequently, accent falls on the fourth or fifth syllable, depending on weight.

(6) a. [ [ loq'o·c-ad-uwad ] u ]

〈lo» «q'o ca•» ( du wá· ) du

'make noise by moving around'

b. [ [ si-de-ac'-iyic' ] in ]

〈si〉 «de c'i·» ( yi c'ín )

'while they were sailing along'

c. [ [ muna $\cdot c-i d]$ upba ]

$\langle\mathrm{mu}\rangle\langle$ na ci·» ( dú? ) ba

'would be shy' 
In summary, several regular processes combine in Kashaya to produce a system of considerable intricacy, in which stress falls on any of the first five syllables depending on the length of the root, the presence of a prefix, and the distribution of closed syllables and long vowels. In the next section, I discuss the role of the Stem constituent within the Word, and how this further complicates the system by affecting the potential application of Foot Flipping.

\section{Level ordering}

The fundamental structure of a Kashaya verb can be illustrated by the following example.

$$
\left[\left[\left[\mathbf{t}^{\prime} \mathbf{e} \cdot \mathbf{t}\right]_{\text {ROOT }} \text { ibic }\right]_{\text {STEM }} \text { ba }\right]_{\text {WORD }}
$$

The length of the root is crucial to the realization of syllable extrametricality, as shown above. But we have not yet covered the nature of the Stem suffixes and the Word suffixes. (The instrumental prefixes in the verb are tightly bound to the root, and can be considered part of a Base to which the Stem suffixes actually attach; see Buckley 1994a.) The crucial fact is that Iambic Lengthening and Foot Flipping apply only to members of the Stem class, and never to the Word class. Before pursuing this point further, however, I make a digression into the content of these two classes.

The Stem level suffixes can be compared to Level 1 in Lexical Phonology (Kiparsky 1982). A Kashaya verb may contain many such suffixes, but often none. They are classified by Oswalt (1961) in various categories that include adverbial meanings (directionals); aspectual changes (inceptive, durative, distributive); and valence (reflexive, reciprocal, causative). All are optional for verbs in general, although by lexical property, for example, some obligatorily occur with a durative suffix.

The Word level (or Level 2) suffixes always follow whatever Stem suffixes are present in the verb. This class mainly consists of members of a large group of suffixes, exactly one of which must be present in every verb. This slot covers several types of function, including mood 
(imperative, conditional); evidentials (visual, aural, circumstantial, hearsay); switch reference (same or different subject plus temporal sequence); and the absolutive, which marks perfective verbs as well as functioning as an infinitive and creating derivative nouns and adjectives. A few other suffixes can precede or follow this slot, but are optional: examples are negation, remote past, the "responsive" for an utterance made in response to what someone else has said, and relative clause markers.

It should be clear from these descriptions that there is not an obvious means of attributing the difference between the Stem and Word suffixes to another notion such as derivational or inflectional functions. It should be possible, however, to define a position in an elaborated set of functional projections at which one shifts from Stem to Word: nodes such as aspect and causative would appear below this position, but mood and evidential would appear above it. In an approach such as Distributed Morphology (Halle \& Marantz 1993), the phonological operations of Iambic Lengthening and Foot Flipping would apply in cycles of Vocabulary Insertion until the relevant point is reached, after which those processes no longer apply. It would also be possible to treat the Stem and Word classes as arbitrary diacritics on all suffixes on the verb, so that a rule such as Iambic Lengthening will apply only to those bearing the Stem diacritic.

As discussed below, this point is tangential to the question of how the application of these processes to the Stem suffixes is affected by the nature of the first (and possibly only) occurring Word suffix. In particular, the latter element does not participate in Foot Flipping, but it does affect the syllable structure of the Stem suffixes and determines whether these eligible suffixes actually undergo Flipping. That question is central to this paper, and I will return to it once the different behavior of Stem and Word suffixes has been demonstrated. 


\subsection{Stem-level phenomena}

As mentioned, Iambic Lengthening and Foot Flipping apply only to suffixes in the Stem class; this will be shown in the following section, and is the main relevance of the Stem category for the phenomena analyzed in this paper. Before turning to those data, however, I briefly discuss other motivations for the special status of the Stem as distinct from the Word.

An important additional pattern related to vowel length is Elision of a vowel preceded by another vowel. The outcome is a long vowel when both are located within the Stem (a), but a short vowel if the second, or both, vowels are from Word suffixes (b).

a. [ [ bane-aduc ] ? ]

〈ba〉 «ne·» ( dú? )

'send away'

b. [ cahno ] inna-em ]

«cah〉 ( nón ) ( nam ) * * *ah〉«non» ( nám )

'I heard someone singing'

c. $[$ siwi·c $]$ me? $]$

$\langle\mathrm{si}\rangle\left\langle\mathrm{wic}^{\mathrm{h}} \gg(\right.$ mé? $) \quad *\langle\mathrm{si}\rangle\left(\mathrm{wíc}^{\mathrm{h}}\right)(\mathrm{me}$ )

'hang! (pl)'

This evidence is a bit subtle, because a long vowel in a closed syllable regularly shortens; but such vowels opaquely undergo stress shift in a counterbleeding relation, as shown by the underlying long vowel in (c). The lack of this shift in (b) proves that the immediate outcome of Elision was a short vowel, so that it applies differently in the Stem and Word levels.

One segmental process that occurs only within the Stem (as both trigger and undergoer) is Sonorization of postvocalic /c/ to /y/ preceding various combinations of the vowel /i/ and the consonant /c/. A less straightforward example is an operation that Oswalt (1961) calls the 
Decrement; it involves deletion of a laryngeal consonant $/ \mathrm{h} \mathrm{P} / \mathrm{in}$ a restricted distribution preceding the first foot syllable of the word, in fact. The relevance here is that this process is triggered by several kinds of suffixes, especially directionals and plurals, but all are in the larger Stem class. Several other processes, notably Aspirate Dissimilation and Height Harmony, might reasonably be restricted to the Stem level as a formal property because they occur only between prefixes and roots, but this depends partly on exactly how they are formulated and what overall architecture is assumed for the grammar. All of these processes are covered more thoroughly in Buckley (1994a). ${ }^{1}$

\subsection{No word-level Lengthening}

We have already seen many examples of Stem suffixes that undergo Lengthening and Flipping, but the words chosen have not been of the right structure to demonstrate that Word suffixes definitely resist these changes to vowel length. The following examples show a vowel belonging to a Word suffix that heads a foot in an open syllable, but remains short.

a. [ [ mo-mac-ed ] ela ]

$($ mo má· $)($ ce de $)$ la

* ( mo má· $)($ ce de $\underline{\text { }})$ la

'I keep running in there'

\footnotetext{
${ }^{1}$ Buckley (1994a) proposes a Lexical Phonology analysis of Kashaya that uses five levels. Some of the patterns that motivated certain level distinctions can be handled by other theoretical means, and so here I maintain a simpler binary distinction. The Stem level is mainly those suffixes that were added in Level 3, and the Word level is mainly Level 5 but also including the few suffixes assigned to Level 4. Levels 1 and 2 were primarily the locus of limited operations such as prefixation and reduplication; there may still be motivation for a level before the Stem, perhaps a Root level, but this does not interact with the problem addressed in this paper.
} 
b. [ [ hot $\left.{ }^{\text {th-ala }}\right]$ s'uw-em ]

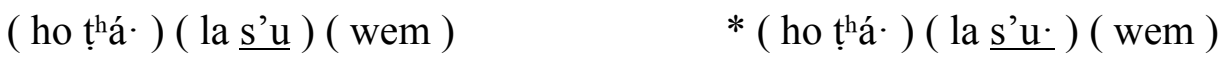

'it would warm (us) up'

c. [ [ s'i-yic' ] Pcid-thi-mi-ya-em ]

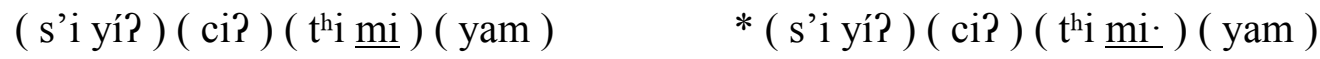

'they never used to do (that)'

This generalization is true even if the vowel in the Word suffix is the nucleus of the main-stress syllable, with or without the effect of syllable extrametricality.

(10) a. $\quad[$ [ s'i $]$ phila $]$

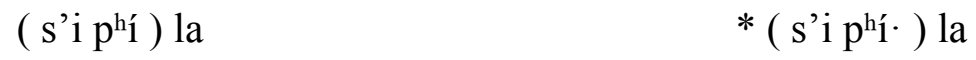

'if it happens'

b. [ [ bawil ] ela ]

〈ba〉 ( wi lé ) la $\quad *$ ba〉 ( wi lé· ) la

'I am putting (it) in'

c. [ [ ca-hke ] wi-ya-e· ]

〈cah〉 ( ke wí) ( ye· ) * *cah〉 ( ke wí· ) ( ye• )

'it blocked me from sitting'

\subsection{No word-level Flipping}

Foot Flipping occurs only if the entire $\mathrm{Cv} \cdot \mathrm{Cv}$ target of the process is located in the Stem; otherwise the $\mathrm{Cv} \cdot$ remains a nonbranching (and extrametrical) foot.

(11) a. $\left[\left[\mathbf{q}^{\prime} \mathbf{a} \cdot\right]\right.$ mela $]$

«q'a’» ( me lá )

* «q’a me·» ( lá )

'I left' 
b. $[[\operatorname{sima} \cdot \mathbf{q}]$ eti $]$

$\langle$ si $«$ ma $\gg$ ( qa tí )

* 〈si « «ma qa`» ( tí )

'although he's asleep'

c. [ [ šo-t’'o· ] thi-phila ]

〈šo〉«ț’’’» ( thi phí ) la

* 〈šo〉 «ț’o thi $\cdot »\left(p^{\mathrm{h} i ~ l a ́ ~}\right)$

'if (you) don't peel it'

These pairs of grammatical and ungrammatical outcomes do not differ in the location of stress, since shift occurs in either case, but they do differ in the distribution of vowel length; the correct forms show that Flipping has not occurred.

The following pairs have the identical prosodic structure $\mathrm{Cv} \cdot \mathrm{Cv}$ in the input, but differ in whether the last vowel is part of a Word or Stem suffix. Only in the latter case does Flipping occur; that is, the Stem-level suffix undergoes Foot Flipping, but not the Word-level suffix under the same syllable configuration, which retains the underlying distribution of vowel length.
a. $\left[\left[\mathbf{q}^{\prime} \mathbf{a} \cdot\right]\right.$ mela $]$
$[[\mathbf{q} \cdot \mathbf{a} \cdot$-cid $]$ u $]$
«q'a·» ( me lá )
«q'a ci·» ( dú )
'I left'
'keep leaving'
b. [ [ sima·q ] eti ]
$[[\operatorname{sima} \cdot \mathbf{q}-\mathrm{ad}] \mathrm{u}]$
〈si «
〈si〉 «ma qa`» ( dú )
'although he's asleep'
'usually sleep'
c. [ [ qa-ț'o• ] wi-ya-e· ]
[ [ qa-ț'o-cid-uced ] u ]
〈qa〉 «ṭ’o•» (wi yé· )
〈qa〉 «ṭ’o ci •»( du cé• $)$ du
'rubbed off my (skin)'
'be peeling with the teeth'

Note that a stressed degenerate foot is permitted when necessary, so this cannot be what causes avoidance of Flipping in the Word level. 


\subsection{No Flipping before CVC}

We turn now to a phonological condition on Flipping that plays a crucial role in the interaction between Stem and Word. Since Flipping applies to $\mathrm{Cv} \cdot \mathrm{Cv}$, it is blocked in $\mathrm{Cv} \cdot \mathrm{CvC}$; more generally, if the point of Flipping is to create a perfect iamb, then it could operate on $\mathrm{Cv} \cdot \mathrm{CvC}$ unless it simply deleted the vowel length to create $\mathrm{CvCvC}$, but this is not a permitted outcome. This phonological blocking of Flipping is also true fully within the Stem Level, as in $(4 a, b)$ above.

But now we come to the crux of the problem. In the following pairs, the first example fails to undergo Flipping due to a $\mathrm{CvC}$ syllable; the second example in each case shows that the same root and suffix combination can indeed undergo Flipping if the syllable structure is different.
a. $\quad[$ ['a·-cid $]$ ba $]$
$[[\mathbf{q} \cdot \mathbf{a} \cdot$-cid $] \mathrm{u}]$
«q'a·» ( cín’) ba
«q’a ci•» ( dú )
'after leaving'
'keep leaving'
b. $\quad\left[[\operatorname{sima} \cdot \mathbf{q}-\mathrm{ad}] \mathrm{t}^{\mathrm{h}}-\mathrm{e}\right]$
[ [ $\operatorname{sima} \cdot \mathbf{q}-\mathrm{ad}] \mathrm{u}]$
〈si〉 «ma·» ( qá? ) the
〈si〉 «ma qa•» ( dú )
'can't sleep'
'usually sleep'
c. [ [ qa-t'o ${ }^{\prime}-$ cid $\left.] \mathrm{t}^{\mathrm{h}} \mathrm{u}\right]$ ?
[ [ qa-t'o $\mathbf{0}$-cid-uced ] u ]
〈qa〉 «ṭ’o•» ( cí? ) ( th th $\left.^{\mathrm{h}}\right)$
〈qa〉 «ṭ’o ci·» ( du cé• $)$ du
'don't peel (it)!'
'be peeling with the teeth'

The formal problem here is that the only reason the $\mathrm{CvC}$ syllable exists to affect the application of Flipping to the Stem suffix is that the following Word suffix begins with a consonant. That is, Flipping has to apply only within the Stem Level suffixes, but whether $\mathrm{CvC}$ blocks Flipping depends on a Word Level suffix. 
This pattern is the seemingly global effect that I wish to address here, and in the following sections I discuss the ways in which various theoretical approaches can, or cannot, handle this phenomenon.

\section{Ordering analysis of Lengthening}

Let us return for a moment to the simpler case of Iambic Lengthening. In a theory with ordered operations, a straightforward way to analyze the fact that Stem suffixes undergo it and Word suffixes do not is to add all Stem suffixes and apply the rule (a); then add any Word suffixes, but not to apply the rule again (b).

(14) a. [ hoț $^{\mathrm{h}}$-ala ]

( ho țá' ) la

b. [ [ (hot thá·)la ] s'uw-em ]

( ho ṭ̂á· ) ( la s’u ) ( wem )

This approach can be implemented in Lexical Phonology (Buckley 1994a) as well as in any serial theory that permits an intermediate representation of the Stem to which phonological processes apply, including phases in Distributed Morphology (see below).

A complication arises in intermediate representations, however, which is that when the rule applies to the Stem representation, a consonant at the end of the (intermediate) word has to be ignored, or extrasyllabic, in order to permit Lengthening to apply. This is necessary since that final syllable often ends up as open due to the following Word suffix.

a. [ mo-mul-ic'-ed ]

( mo mú· ) (li c’e· ) d'

b. [ [ mo-mul-ic'-ed ] u ]

( mo mú $\cdot)($ li c'e· $)$ du 'run in circles' 
If the syllable ends up closed because the Word suffix begins with a consonant, it will shorten again independently without making any false predictions about the location of stress.

(16) a. [ mo-mul-ic'-ed ]

( mo mú· ) (li c'e· ) d'

b. [ [ mo-mul-ic'-ed ] ba ]

( mo mú· ) ( li c'en' ) ba 'after running in circles'

In this case, look-ahead is not crucial; but Flipping is more complicated. When we see just the Stem with extrasyllabicity, Flipping should apply (a); but we can't predict whether we will eventually have $\mathrm{CvC}$ or $\mathrm{Cv}(\mathrm{b})$.

a. $\left[\mathbf{q}^{\prime} \mathbf{a} \cdot-\operatorname{cid}\right]$

$\ll q^{\prime}$ a ci $\bullet » d^{\prime}$

b. $\left[\left[\mathbf{q}^{\prime} \mathbf{a} \cdot\right.\right.$-cid $]$ ba $]$

[ [ q'a·-cid ] u ]

«q'a·» ( cín’) ba

«q’a ci·» ( dú )

'after leaving'

'keep leaving'

We cannot simply undo Flipping at a later point by shortening the vowel as the result of the consonant syllabifying in the coda (b), as we can with Iambic Lengthening, because this generates the wrong result whether or not stress shift also applies (c).

a. [ [ q'a'-cid ] ba ]

«q'a ci·»d' ba

b. «q'a ci·n'»ba

c. * «q'a cin’» ( bá )

* ( q'a cín' ) ba 
The important analytical question, then, is how to prevent the application of Foot Flipping within the Stem domain or level, on the basis of whether or not a Word level suffix begins with a consonant or a vowel.

\subsection{Avoiding look-ahead}

Buckley $(1994 a, b)$ splits the effect of Foot Flipping into two steps in a Lexical Phonology framework; the trick is to set up the conditions for Flipping at the Stem level, but not to complete the operation until the Word level, when the final syllabification is known. Although in that analysis the difference was between levels 3 and 4, the same approach transfers to a two-level model.

The first step under this analysis is to set the stage for Flipping by adjoining a Cv syllable to a preceding $(\mathrm{Cv} \cdot)$ foot, creating the anti-iamb $(\mathrm{Cv} \cdot \mathrm{Cv})$, which has the opposite internal weight relationship of a usual iamb $(\mathrm{CvCv} \cdot)$. This is all that occurs at the Stem level (a). Then, at the Word level, if the existing prosody requires a $\mathrm{C}$ to be moved into the preceding syllable, the antiiamb is destroyed and new foot structure is created, because two heavy syllables cannot occur in one quantity-sensitive foot (b). But if no such resyllabification is necessary, the anti-iamb remains available to undergo the remaining half of the process, which is the actual Flipping of vowel length.

(19) a.

Basic Footing $\quad\left(q^{\prime} a \cdot\right)$ ci $\quad d^{\prime}$

CV Adjunction $\quad\left(\mathrm{q}^{\prime} \mathrm{a} \cdot \mathrm{ci}\right) \quad \mathrm{d}^{\prime}$

b. $\left[\left[\mathbf{q}^{\prime} \mathbf{a} \cdot\right.\right.$-cid $]$ ba $]$

(q'a ci) d ba

«q'a•» ( cin') ba c. $\left[\left[\mathbf{q}^{\prime} \mathbf{a} \cdot\right.\right.$-cid $\left.] \mathrm{u}\right]$

$\left(q^{\prime} a \cdot c i\right) d u$

«q’a ci·» du 
This two-stage architecture clearly captures the strong Stem vs. Word distinction, and correctly predicts (for example) that all Stem affixes are internal to all Word affixes. In a rule-based implementation, the rules of Iambic Lengthening and CV Adjunction simply turn off at the end of the Stem level, accounting for the fact that no Word suffixes participate in these processes.

There are, however, significant disadvantages. First, this derivation splits Flipping into two processes, but not because the phenomenon inherently seems to demand it; rather, this strategy is necessary to achieve the effect of global look-ahead without such a formal mechanism. Further, the temporary anti-iamb violates the general pattern of Kashaya as well as languages in general (Prince 1990); it seems more a trick to get the facts to come out right than an insight. Finally, the analysis makes no connection between Flipping and Lengthening, yet both are fundamentally about changes in vowel length. I turn now to an alternative analysis that avoids these problems, but raises other questions.

\subsection{Constraint Domains}

Look-ahead is an issue in a stepwise, local theory that is restricted in the amount of information that can be seen at a particular stage, but as Kashaya demonstrates this restriction may be too strong. Optimality Theory (Prince \& Smolensky 1993) avoids the look-ahead problem because it evaluates the output directly, with surface syllabification present: the form of the Stem, with or without Flipping, is evaluated in a candidate that already contains Word suffixes. But the classic form of the theory, without separate lexical levels, requires some other means of identifying the lengthening suffixes; either a long (essentially arbitrary) list of morphemes that undergo certain changes, or some domain equivalent to the Stem.

Buckley $(1996,1997)$ takes the latter approach, proposing Constraint Domains: substrings

of the output that we can here call Stem and Word, as well as constraints indexed such that they are relevant only to segments located in a specific domain. The domain constituents, marked by \{\} , line up with the morphological bracketing, but are not nested. 
(20)

a. $[[\operatorname{sima} \cdot \mathbf{q}]$ eti $]$

$$
\{\text { si ma. q }\}_{\mathrm{s}}\{\text { e ti }\}_{\mathrm{w}}
$$

$\langle$ si $«$ ma·» ( qa tí ) b. $[[\operatorname{sima} \cdot \mathbf{q}-\mathrm{ad}] \mathrm{u}]$

$$
\begin{aligned}
& \{\text { si ma' qa d }\}_{\mathrm{s}}\{\mathrm{u}\} \mathrm{w}_{\mathrm{w}} \\
& \langle\text { si } \ll \text { ma qa } »(\text { dú })
\end{aligned}
$$

Crucially for Kashaya, the constraint IDENT-LENGTH occurs in a special version, IDENT$\operatorname{LENGTH}_{\{\mathrm{W}\}}$, which is violated by any changes to the length of a vowel that occur in the Word domain. High ranking ensures that Word suffixes are faithful to underlying length, whereas Stem suffixes are subject to a lower-ranked version of the same constraint. We also require some contraint, or combination of constraints, that force Flipping to occur; here I simply use

\begin{tabular}{|c|c|c|c|}
\hline$\{\operatorname{sima} \cdot \operatorname{qad}\}_{\mathrm{S}}\{u\}_{\mathrm{W}}$ & IDENT- $_{\mathrm{W}}$ & $*(\mathrm{Cv} \cdot) \mathrm{Cv}$ & IDENT-L $\mathrm{L}_{\mathrm{S}}$ \\
\hline a. $\langle$ si $\rangle\langle m a \cdot »($ qa dú) & & *! & \\
\hline$\notin \quad$ b. $\langle$ si $\rangle\langle m a ~ q a \cdot »(d u ́)$ & & & $* *$ \\
\hline$\{\operatorname{sima} \cdot \mathrm{q}\}_{\mathrm{s}}\{\mathrm{eti}\}_{\mathrm{w}}$ & IDENT- $_{\mathrm{W}}$ & $*(\mathrm{Cv} \cdot) \mathrm{Cv}$ & IDENT-L $\mathrm{L}_{\mathrm{S}}$ \\
\hline c. $\langle$ si $\rangle\langle m a \cdot »($ qa tí) & & $*$ & \\
\hline d. $\langle$ si $\rangle\langle\mathrm{ma} \mathrm{qa} \cdot »(\mathrm{tí})$ & $* !$ & & $*$ \\
\hline
\end{tabular}
$*(\mathrm{Cv} \cdot) \mathrm{Cv}$, prohibiting a long-vowel foot followed by an open syllable.

This ranking prevents changes in length (though not in segmental features) within the suffix -eti, but allows Flipping to modfiy -ad. A major success of this approach is that the same faithfulness constraint blocks Iambic Lengthening and long-vowel Elision in Word suffixes, thereby unifying the three phenomena in a way that was not possible in the rule-based approach. ${ }^{2}$

\footnotetext{
${ }^{2}$ In certain other approaches, such as cophonologies (Orhan 1996), these generalizations might be considered a relic of a previous stage in the diachrony of the language and require no synchronic formalization, but the pattern in Kashaya remains extremely robust. Such a theory predicts that the lengthening property could be randomly distributed among the suffixes; as a result, at least from the
} 
There are also additional advantages, such as no need for temporary final extrasyllabicity of the stem-final consonant. Most centrally, because the entire form is present in the candidates under evaluation, there is no need to look ahead to whether an eventual following Word suffix will begin with a consonant or a vowel.

\begin{tabular}{|c|c|c|c|}
\hline$\left\{\mathrm{q}^{\prime} \mathrm{a} \cdot \mathrm{cid}\right\}_{\mathrm{S}}\{\mathrm{u}\}_{\mathrm{W}}$ & IDENT- $_{\mathrm{W}}$ & $*(\mathrm{CV} \cdot) \mathrm{CV}$ & IDENT- $_{S}$ \\
\hline a. «q'a·»(ci dú) & & $* !$ & \\
\hline b. «q'a ci·» (dú) & & & $* *$ \\
\hline$\left\{\mathrm{q}^{\prime} \mathrm{a} \cdot \mathrm{cid}\right\}_{\mathrm{S}}\{\mathrm{ba}\}_{\mathrm{W}}$ & IDENT-L $_{\mathrm{W}}$ & $*(\mathrm{CV} \cdot) \mathrm{CV}$ & IDENT $_{-} \mathrm{L}_{\mathrm{S}}$ \\
\hline c. «q'a·» (cín’) ba & & & \\
\hline d. «q'a ci·n’» (bá) & & & $* ! *$ \\
\hline e. «q’a cin’» (bá) & & & $* !$ \\
\hline
\end{tabular}

Because the conditions for Foot Flipping are not met in the presence of a following closed syllable, (c) wins for simple phonological reasons, without any complicated reference to what will happen later in the derivation. Among the disadvantages of this approach for the analysis of Kashaya is the stipulation of the Stem vs. Word distinction; these domain successfully capture the fact that the suffixes of each group occur in contiguous strings, but they are laid on top of the representation, rather than forming part of architecture as in Lexical Phonology. In addition, there is no inherent account for opacity; this would require extra mechanisms, just like all Classic OT frameworks.

formal structure of the synchronic grammar, it remains a coincidence that vowel length is the common property distinguishing the same sets of affixes with regard to Lengthening, Flipping, and Elision. 
Opacity is a particular problem at the Phrasal level in Kashaya, where accentual feet are often constructed across two words. Although there is considerable variation in the occurrence of these phrases (Buckley \& Gluckman 2012), they are clearly distinct from the lexical feet for Iambic Lengthening and Flipping. As pointed out to me by Paul Kiparsky, the Constraint Domains theory appears to predict that Foot Flipping should occur across word boundaries; but there is no Flipping in phrases, just Foot Extrametricality.

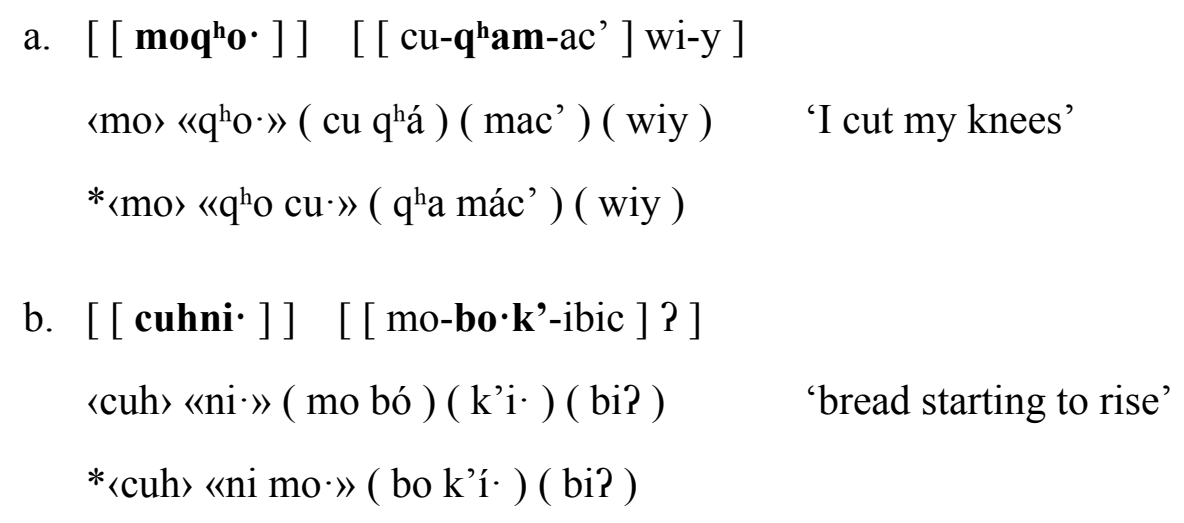

Assuming that monomorphemic stems such as $/ \mathrm{moq}^{\mathrm{h}} \mathrm{o} \cdot /$ 'knee' and /cuhni $/$ 'bread' consist of coterminous Stem and Word domains, the entire sequences $/ \mathrm{q}^{\mathrm{h}} \mathrm{o} \cdot \mathrm{cu} /$ and $/ \mathrm{ni} \cdot \mathrm{mo} /$ are in Stem domains and changes to vowel length there ought to be permitted: both vowels are subject to lower-ranking IDENT-LENGTHs. This difficulty could be solved by having a distinction between Lexical and Postlexical components in the grammar, where in the latter component Flipping is ruled out by a different constraint ranking. This is probably already a necessary enhancement to the architecture of the grammar (e.g., Ito \& Mester 2003); but if we are abandoning the pure onestep format of Classic OT by introducing stages in the representation, we should also consider introducing ordered components to handle Stem vs. Word also.

\subsection{Stratal Optimality Theory}

Stratal OT, in various specific forms (Kiparsky 2000, Bermúdez-Otero 2011), is an implementation of the basic Lexical Phonology architecture in a constraint-based framework, with fixed stages in the derivation labeled Stem, Word, and Phrase. The output of level $n$ is the input to 
level $n+1$, but within each level forms are chosen by ranked constraints rather than rules. Following Bermúdez-Otero, I assume that each level (or stratum) is internally global like Classic OT; but under standard assumptions, globality does not extend across levels. Because the account of the Stem and Word difference requires that vowel length changes occur in the Stem level, stratum-internal globality will not remedy the look-ahead problem discussed above. In fact, in this regard, Stratal OT is exactly like Lexical Phonology, and still needs some equivalent to $\mathrm{CV}$ Adjunction in the Stem level. On top of this, the arbitrary nature of CV Adjunction is harder to manage with constraints than with a processual rule; for example, we predict Iambic Lengthening at the Word level if foot form constraints dominate IDENT-LENGTH, as would be expected for Flipping to be implemented there. Is there an alternative to CV Adjunction?

A possible solution is to go halfway not in the creation of the iambic foot, but rather in the shift of the mora. ${ }^{3}$ Foot Flipping, of course, involves a change from $\mathrm{Cv} \cdot \mathrm{Cv}$ to the perfect iamb $(\mathrm{CvCv} \cdot)$. An intermediate anti-iamb $(\mathrm{Cv} \cdot \mathrm{Cv})$ is especially problematic because the right branch is light, whereas Iambic Lengthening, which is highly active in the Stem level of Kashaya, demands a heavy right branch. Suppose that the Stem level output represents a compromise between preserving the length on the first vowel (demanded by faithfulness) and lengthening the second vowel (to yield the preferred heavy foot head). This can be effected by doubly linking the middle mora in the foot to both vowels.

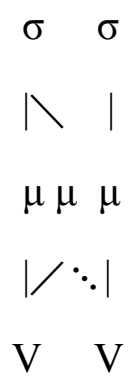

\footnotetext{
${ }^{3}$ For reasons of space, I do not discuss several other possible approaches to moraic representations that raise various problems. This analysis builds on a suggestion by Peter Svenonius at the conference.
} 
Admittedly this $(\mathrm{Cv} \cdot \mathrm{Cv} \cdot)$ foot, with a double-linked mora, is a rather unusual configuration. Formally, it may require a separate moraic plane to accomodate links between onset consonants and syllables not shown here. At the same time, the Kashaya pattern is also typologically unusual, and this representation seems no more problematic than the anti-iamb. The lack of vowel shortening in the Stem level - i.e. the mora does not simply shift immediately matches the fact that no other vowel shortening occurs in the Stem level, other than some morphologically determined changes (Buckley 1994a). This suggests two separate constraints, essentially IDENT-LONG >> IDENT-SHORT, similar to the symmetrical pair MAX and DeP applied to moras (McCarthy 2008).

In the Word level, the temporary $(\mathrm{Cv} \cdot \mathrm{Cv} \cdot)$ structure is resolved in favor of a standard $(\mathrm{CvCv} \cdot)$ iamb where possible, but if the second syllable becomes closed, the mora remains with the first vowel as $(\mathrm{Cv} \cdot)(\mathrm{CvC})$, effectively undoing the Stem level spreading. In outline, this derivation recapitulates the $\mathrm{CV}$ Adjunction approach, but directly via the moraic structure (the locus of vowel length) rather than foot structure. Of several approaches I have considered, I believe this is the least problematic means of capturing in Stratal OT the technique used by Buckley $(1994 \mathrm{a}, \mathrm{b})$ to avoid a true look-ahead mechanism. But I turn now to other possibilities that admit a limited degree of globality while maintaining more conventional representations of syllable and foot structure.

\section{Global effects}

Both the CV Adjunction and doubly linked mora approaches described in the previous section rely on an otherwise unattested and also problematic representation to navigate the relative roles of Stem and Word phonology in determining whether Foot Flipping occurs in a particular word. In this section, I discuss several approaches that do not rely on intermediate forms of this type, but rather employ limited types of globality or related techniques to generate the necessary effect. 


\subsection{Global syllabification}

It should be clear that the essential analytical problem lies in the fact that syllabification at the Word level seems to determine whether a process applies at the Stem level. One tack is to incorporate this influence directly into the theory. Remaining in the Stratal OT framework, we might propose a constraint GLOBALSYL that looks at next-level output syllabification and penalizes any segment whose syllable role in a given candidate is distinct from its later correspondent. For Foot Flipping, the Stem level will make reference to the immediately following level, the Word; but the general claim would also permit reference to Word/Phrase differences due to resyllabification across word boundaries.

As formulated, an unsyllabified consonant satisfies the constraint vacuously: it looks only for distinct syllabifications. Such configurations are independently penalized, however, due to PARSE, so such candidates are preferred only when motivated by GLOBALSYL.

\begin{tabular}{|c|c|c|c|c|}
\hline Stem: /q'a·-cid/ & GLOBALSYL & PARSE & $* \mathrm{CV} \cdot \mathrm{CV}$ & IDENT-L \\
\hline a. (q'a) (cid) & & & & \\
\hline b. (q'a) ci d' & & $* !$ & $*$ & \\
\hline c. (q'a ci·) d' & & $* !$ & & $* *$ \\
\hline \hline Word: q'a cin' ba & & \multicolumn{4}{l}{} \\
\hline
\end{tabular}


(26)

\begin{tabular}{|c|c|c|c|c|}
\hline Stem: /q'a'-cid/ & GLOBALSYL & PARSE & ${ }^{*} \mathrm{Cv} \cdot \mathrm{Cv}$ & IDENT-L \\
\hline a. $\left(q^{\prime} a \cdot\right)(\mathrm{cid})$ & $* !$ & & & \\
\hline b. $\left(q^{\prime} a \cdot\right)$ ci d' & & * & *! & \\
\hline c. $\left(q^{\prime}\right.$ a ci $\left.\cdot\right) d^{\prime}$ & & * & & $* *$ \\
\hline
\end{tabular}

This ranking leads to contingent non-syllabification: when the Stem-final C is in an onset in the Word, it is unsyllabified in the Stem in order to avoid a violation of GlobALSYL. ${ }^{4}$ This in turn permits Foot Flipping to occur at the Stem level, and also prevents coda processes from wrongly applying to such consonants (Rice 1990). In fact, it eliminates the need for general extrasyllabicity at the Stem level; instead, the effect of final consonsonant extrasyllabicity is forced exactly when motivated by a later onset position. Otherwise, a Stem coda directly blocks Foot Flipping for phonological reasons, as it would if the $\mathrm{C}$ were in the coda for entirely Stem-internal morphology. IDENT-LENGTH is still ranked higher in the Word level, but it has no global effect.

\subsection{Precompiled prosody}

Global Syllabification certainly does the job, but requires true look-ahead. A different approach is inspired by Hayes' (1990) work on the way that postlexical conditions can apparently affect lexical derivations. Hayes argues that in some languages, alternations according to syntactic context actually involve lexical processes. His solution is PRECOMPILATION of two alternate forms in the lexical phonology, indexed for the syntactic context in which they occur; the appropriate form is inserted into the syntax with its phonological form already determined.

\footnotetext{
${ }^{4}$ Syllabification of the $\mathrm{C}$ in the Word level is based straightforwardly on the following segment there. This simultaneous consideration of Stem and Word forms has some affinities to OT with Candidate Chains, discussed below.
} 
A similar formalism might be applied here to capture the Stem and Word interaction. Specifically, the Stem level could generate two outputs that later compete with each other at the Word level, according to the prosody that is present. Since the two forms need to differ in their expectations about prosody, they must reflect an optional presence of final-consonant extrasyllabicity, where in the forms under discussion Foot Flipping will occur only in the presence of that extrasyllabicity (b).
a. $\left[\mathbf{q}^{\prime} \mathbf{a} \cdot\right.$ - cid $]$
b. $\left[\mathbf{q}^{\prime} \mathbf{a} \cdot\right.$ - cid ]
$\left(q^{\prime} a \cdot\right)($ cid $)$
$\left(q^{\prime}\right.$ a ci· $) d^{\prime}$

This then is a syllabification-focused version of precompilation. At the Word level, the two inputs are treated as stem allomorphs, and the choice follows from the existing constraint ranking: the stem is preferred that has a branching iambic foot (by general metrical constraints) as long as it does not require a change in vowel length by Closed-Syllable Shortening (by a higher-ranking faithfulness constraint).

Such changes to vowel length are already penalized in the Word level, and so require no new assertions about the constraint ranking there; but this approach does complicate the nature of optimal candidate selection at the Stem level. But the choices are quite restricted: the final $\mathrm{C}$ is syllabified or not. Perhaps more choices would be available in a language that permits complex onsets, but Kashaya does not. It might also be related to other types of optionality or variation in the phonology. The derivation conflicts, at least in spirit, with the claim that outward-looking allomorphy is never phonological: Bobaljik (2000) and Embick (2010) claim that morphosyntactic conditioning is a more restrictive account for attested stem allomorphy, and that phonological conditioning predicts unattested patterns. The choice of stem is not, strictly speaking, formulated as whether the segment immediately following the stem is a consonant or vowel, but does make reference to the overall phonological well-formedness of the constraints that contain 
one or the other of the available stem forms. Others in this volume, however, argue that this claim may be too strong (references).

\subsection{Suffix classes in Distributed Morphology}

A theoretical approach very different from the globality permitted in OT is Distributed Morphology (DM), which is highly local (Halle \& Marantz 1993). In order to capture the distinct behavior of Stem and Word morphology, suppose that suffixes are classified into two groups, Inner and Outer, and that no Inner suffix can be added once an Outer suffix occurs (Marantz 2007). After addition of the first Outer suffix, a cycle of phonological rules applies to the entire domain preceding the Outer suffix; this corresponds to the Stem in the Stratal OT approach and matches the standard spell-out of a phase-head complement (Chomsky 2001, Kaye 1995).

The Outer suffix does not undergo these rules itself, and therefore should not yet be spelled out (i.e., have its phonological content inserted into the representation). Yet the most general aspect of the prosodic shape of the first Outer suffix has to be available, specifically whether a final $\mathrm{C}$ in the preceding Inner suffix can ultimately be syllabified into the next syllable. This problem suggests a special role for the prosodic structure of a phase head during spell-out, and a more subtle interpretation of the relationship between vocabulary insertion and relative visibility of spelled-out content to phonological rules.

One potential solution would be to spell out the phase head that triggers the Stem cycle, but to exempt this content from the application of the rules, other than syllabification. Such a position, however, would significantly undermine the basic insight of ordered Vocabulary Insertion: once the content has been spelled out, it should be available for phonological rules. To permit insertion for the purposes of syllabification, but then exclude the latest structural node from participation in rules, requires some special status or marking on that node and appears to be quite arbitrary. This gambit would also lead to uncertain predictions about the interaction of phonology and morphology. 


\subsection{OT with Candidate Chains}

Classic OT has parallel derivations in which candidates can deviate from the input form in many ways at once. A rather different implementation of constraint-based evaluation is OT with Candidate Chains, or OT-CC (McCarthy 2007). In this highly serial model, Eval compares candidates that consist of CHAINS of forms, with one step in the chain for every faithfulness violation (so that the derivation is gradual), and each step must be harmonically improving (which serves to avoid certain types of unattested patterns).

Because there are many potential steps in a derivation, changes to the representation can be ordered as in traditional rule-based phonology. OT-CC handles opacity by PRECEDENCE constraints, which can stipulate that the constraint violations that lead to the steps in the chain occur in a particular relative order.

(28) a. in $\operatorname{PREC}(A, B)$ where $A$ and B are basic Faithfulness constraints,

b. a violation of constraint $\mathrm{A}$ has to precede any violation of $\mathrm{B}$ in the chain

c. and no violation of A can follow a violation of B.

For example, to capture an opaque interaction of vowel apocope and coda devoicing, with /pad/ $\rightarrow$ [pat] but $/$ pada $/ \rightarrow$ pad], we need to choose the chain <pada, pad $>$ without devoicing, and reject $<$ pada, pad, pat $>$.
a. <pada, pad>
violation of MAX-V
b. <pada, pad, pat>
violation of MAX-V and then IDENT-VOICE

The constraint Prec(Ident-Voice, MaX-V) makes the correct choice because Ident-Voice cannot be violated after MAX-V, as it is in (b). The two-clause formulation of the constraint also penalizes (a) for violating MAX-V without a prior violation of IDENT-VOICE, but this effect is overridden by higher-ranked FINAL-C, which forces deletion of the final vowel (McCarthy 2007). 
This very brief outline gives us the background to look at a means of integrating the Stem/Word distinction into OT-CC. For this goal we need reference to morphological operations and the class to which each operation belongs. The original form of OT-CC has no account of stratal effects, except possible morpheme-specific rankings or classes of morphemes, such as "Word-level". The Stem vs. Word distinction is a kind of opacity: viewed phonologically, the lack of Lengthening and Flipping in certain suffixes is unexpected. It makes sense, therefore, to analyze the difference as a kind of opacity using PREC constraints, but we have to involve morphology in the PREC constraint in order to do this.

Wolf (2008) proposes a theory of Optimal Interleaving (OI), in which each instance of Vocabulary Insertion occupies a step in the candidate chain. Because OT-CC is serial in orientation, the derivation is similar to Distributed Morphology, but the choice of optimal derivation is constraint-based. Insertion counts as a faithfulness violation, so PREC can then control ordering of spell-out relative to particular phonological changes. We must refer to a Word class of affixes since there are no strata to serve this purpose. ${ }^{5}$

In Kashaya, the main requirement is to prevent Lengthening and Flipping - i.e., a violation of IDENT-LENGTH — from occurring after the spell-out of a Word affix. First consider the simpler case of Lengthening. The constraint PREC(IDENT-L, Insert-Aff $f_{\text {Word }}$ ) penalizes a violation of IDENT-LENGTH after the insertion of any affix in the Word class (the spell-out of its phonological content). In other words, once the first Word affix is spelled out, no more changes in vowel length are permitted; this is the same effect as ranking IDENT-LENGTH higher in the Word level or domain.
a. $<$ mo-DIR $_{\mathrm{S}}-\mathrm{DUR}_{\mathrm{S}}-\mathrm{EVID}_{\mathrm{W}}$,
b. $<$ mo-DIR $_{\mathrm{S}}-\mathrm{DUR}_{\mathrm{S}}-\mathrm{EVID}_{\mathrm{W}}$,
momac-DUR $_{\mathrm{S}}-\mathrm{EVID}_{\mathrm{w}}$, momac-DUR $_{\mathrm{S}}-\mathrm{EVID}_{\mathrm{W}}$, momaced-EVID $\mathrm{w}_{\mathrm{w}}$ momaced-EVID ${ }_{\mathrm{W}}$

\footnotetext{
${ }^{5}$ Thanks are due to Matt Wolf for help in developing this analysis.
} 


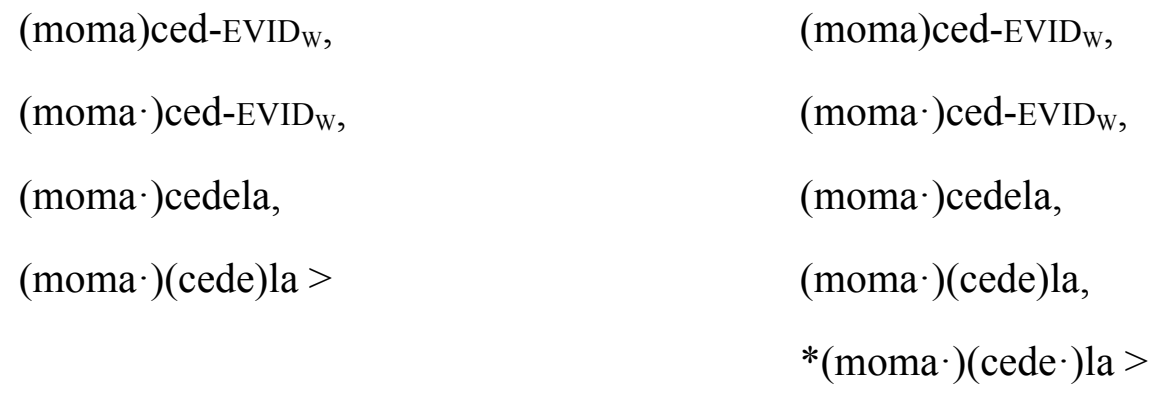

Of these two possible derivations, chain (a) wins because violation of IDENT-LENGTH, i.e. vowel lengthening, occurs after spell-out of the Word affix -ela in (b).

For the analysis of Foot Flipping, we can assume a final extrasyllabic consonant where needed as in the Global Syllabification analysis within Stratal OT, so that Flipping is able to occur before any Word affix is added. The essential constraint rankings are quite similar, with a substitution for the framework at hand.
a. Stratal:
GLOBAL-SYL $>>*(\mathrm{CV} \cdot) \mathrm{CV}>>$ IDENT-L
b. Interleaving:
PREC $>>*(\mathrm{CV} \cdot) \mathrm{CV}>>$ IDENT-L

In order for the analysis to work properly within Optimal Interleaving, however, the two clauses that form an inherent part of PREC in the standard OT-CC theory must be decoupled. Under the original conception of PREC, shown in (28), the constraint PREC(IDENT-L, Insert-Aff $f_{\text {Word }}$ ) requires correctly that a violation of IDENT-L cannot follow insertion of a Word affix, but incorrectly that a violation of the faithfulness constraint has to precede insertion of any Word affix. The latter clause wrongly predicts that gratuitous lengthening will occur in simple derivations such as /ca-ba/ 'having sat', with lengthening to /ca// before adding the Word suffix /ba/.

Wolf (2011) has independently suggested that a revised "split-PREC" theory might be necessary to account for other patterns, but acknowledges that such a revision leads to more kinds of opaque interactions, namely mutual and self-counterfeeding and counterbleeding relations, which are not predicted under the stricter two-clause formulation of McCarthy (2007). 
The Kashaya facts can be seen as supporting Wolf's argument, but also as an additional blow to the typological predictions of the standard theory.

\section{Conclusion}

The Kashaya data present a problem of globality or look-ahead that is fairly simple to summarize but more difficult to analyze. Given a structure [[[Root]X]Y], where X and Y belong to different phonological domains, the phonology of $\mathrm{X}$ makes partial reference to content of $\mathrm{Y}$. But that reference has to be limited to the syllable structure that results from addition of Y, rather than the full presence and participation of $\mathrm{Y}$; otherwise a Word suffix will undergo Stem processes. Different theoretical approaches can accommodate these facts, but with various advantages and compromises to the strictest forms of each theory.

A Lexical Phonology analysis of the Kashaya facts captures the difference between Stem and Word patterns, but has difficulty with cross-level effects, since the theory is designed not to permit global interactions. The use of a temporary ill-formed anti-iamb generates the right outcome, but at the cost of dubious intermediate representations and rule types. Stratal OT generalizes much more effectively over several processes that create long vowels in the Stem but not in the Word, but has the same difficulty with cross-level interaction, despite globality within levels. As with Lexical Phonology, an unusual intermediate form - mostly likely in marked moraic structure - can bridge the Stem/Word divide, but casts doubt on the overall analysis.

Limited forms of globality can be achieved in Stratal OT by adding new tools. The constraint GLOBALSYL provides true look-ahead to the next level, which is a powerful device, although it is strictly limited to syllable structure rather than other properties such as segmental content. Precompiled pairs of outputs of the Stem level, differing only in the syllabification of the final consonant, are also very limited in their effect, but require an unusual kind of allomorph selection at the Word level. Parallel OT easily handles global interactions, but in its original form has no account of stratal behavior. The addition of Constraint Domains creates substrings that 
follow slightly different constraint rankings while maintaining the required globality, but these domains are relatively ad hoc. A significant problem with opacity can be solved by adding a distinct postlexical component, although other types of opacity will require different solutions.

Distributed Morphology is by its very design highly local, and has difficulty accessing outward phonology as required by the Kashaya pattern. It is unclear how the central predictions of the theory might be altered if we permit an affix to reveal its basic prosody and have an effect on syllable structure, without full spell-out and participation in phonological processes. Optimal Interleaving resembles DM in certain important ways, including ordered phonology and morphological spell-out; but because it has the limited global properties of OT-CC, it can capture the effect of the following suffix via the well-formedness of the entire candidate chain. On the other hand, reference to the Word class of affixes is ad hoc, and only a weakened version of the PREC constraint that is central to OT-CC can handle the analysis.

In summary, the unusual phenomenon of Foot Flipping presents a surprisingly difficult challenge for a wide range of theoretical approaches. Depending on what compromises one is willing to make, the challenge might not seem especially grave. But it is indisputable that no theory of phonology in word derivation can be considered empirically adequate if it does not have an account for facts like those presented by Kashaya.

\section{References}

Baker, Adam. 2009. Parallel evaluation in Stratal OT. Ms., University of Arizona.

Bermúdez-Otero, Ricardo. 2011. Cyclicity. The Blackwell Companion to Phonology, vol. 4, 2019-2048. [etc] 
Bobaljik, Jonathan. 2000. The ins and outs of contextual allomorphy. University of Maryland Working Papers in Linguistics, ed. K.K. Grohmann and C. Struijke, vol. 10, pp. 35-71. UMCP.

Buckley, Eugene. 1994. Persistent and cumulative extrametricality in Kashaya. Natural Language and Linguistic Theory 12, 423-464.

Buckley, Eugene. 1996. Levels vs. domains: the case of Kashaya vowel length. Proceedings of the Berkeley Linguistics Society 22, 36-45.

Buckley, Eugene. 1997. Optimal iambs in Kashaya. Rivista di Linguistica 9, 9-52.

Buckley, Eugene. 2009. Locality in metrical phonology. Phonology 26, 389-435.

Buckley, Eugene \& John Gluckman. 2012. Syntax and prosody in Kashaya phrasal accent. $U$. Penn Working Papers in Linguistics 18, 21-30.

Chomsky, Noam. 2001. Derivation by phase. Ken Hale: A Life in Language, ed. M. Kenstowicz, 1-52. MIT Press.

Embick, David. 2010. Localism versus Globalism in Morphology and Phonology. MIT Press.

Halle, Morris \& Alec Marantz. 1993. Distributed morphology and the pieces of inflection. The View from Building 20, ed. K. Hale \& S.J. Keyser, 111-176. MIT Press.

Hayes, Bruce. 1990. Precompiled phrasal phonology. The Syntax-Phonology Connection, ed. S. Inkelas \& D. Zec, 85-108. CSLI.

Hayes, Bruce. 1995. Metrical Stress Theory: Principles and Case Studies. University of Chicago Press

Ito, Junko \& Armin Mester. 2003. Lexical and postlexical phonology in Optimality Theory: evidence from Japanese. Linguistische Berichte. Sonderheft 11: Resolving Conflicts in Grammars, ed. Gisbert Fanselow \& Caroline Féry. 183-207.

Kager, René. 2001. Rhythmic directionality by positional licensing. Handout of presentation given at HILP-5, University of Potsdam, January 11.

Kager, René. 2012. Stress in windows: Language typology and factorial typology. Lingua 122, 1454-1493. 
Kaye, Jonathan. 1995. Derivations and Interfaces. Frontiers of Phonology, ed. J. Durand \& F. Katamba, 289-332. Longman.

Kiparsky, Paul. 1982. Lexical Morphology and Phonology. Linguistics in the morning calm: selected papers from SICOL-1981 (vol. 1), ed. In-Seok Yang for the Linguistic Society of Korea, 3-91. Seoul: Hanshin Publishing Company.

Kiparsky, Paul. 2000. Opacity and cyclicity. The Linguistic Review 17, 351-367. [etc]

Marantz, Alec. 2007. Phases and words. Phases in the theory of grammar, ed. S.-H. Choe, 191122. Dong In.

McCarthy, John. 2003. OT constraints are categorical. Phonology 20, 75-138.

McCarthy, John. 2007. Hidden Generalizations: Phonological Opacity in Optimality Theory. Equinox.

McCarthy, John. 2008. Doing Optimality Theory: Applying Theory to Data. Blackwell.

Orgun, Cemil Orhan. 1996. Sign-based morphology and phonology with special attention to Optimality Theory. Dissertation, University of California, Berkeley.

Oswalt, Robert L. 1961. A Kashaya grammar (Southwestern Pomo). Dissertation, UC Berkeley.

Oswalt, Robert L. 1964. Kashaya texts. University of California Press.

Prince, Alan. 1990. Quantitative consequences of rhythmic organization. Parasession on the Syllable in Phonetics and Phonology, 355-398. Chicago Linguistic Society.

Rice, Keren. 1990. Predicting rule domains in the phrasal phonology. In S. Inkelas \& D. Zec (eds.), The Phonology-Syntax Interface. CSLI, Stanford and University of Chicago Press, 289-312.

Wolf, Matthew. 2008. Optimal Interleaving: Serial phonology-morphology interaction in a constraint-based model. Dissertation, UMass Amherst.

Wolf, Matthew. 2011. Limits on global rules in Optimality Theory with Candidate Chains. Phonology 28, 87-128. 


\begin{abstract}
$\underline{\text { Abstract }}$
The complex patterning of Kashaya stress and vowel length depends on the morpheme in which participating vowels are located. The verb root and Stem suffixes undergo various length alternations, whereas Word suffixes resist them. The special challenge is that whether a Stem vowel participates in these alternations can depend on syllable structure that is partly determined by a following Word suffix. This means that if the relevant rules or constraints apply before addition of Word suffixes, such as in a stratal approach, some kind of look-ahead or globality is required; but if the crucial Word suffix is present when the vowel alternations occur, there must be some mechanism to limit the participation of that suffix. In this paper I explore the complex interaction between the changes to vowel length and the morphological affiliation of the morphemes in question, and consider the challenges that these facts present to a range of ruleand constraint-based theories of morphophonology.
\end{abstract}

\title{
$\underline{\text { Keywords }}$
}

stress

vowel length

strata

globality

rules and constraints 